\title{
Special section on The Human Side of Service Engineering
}

(C) Springer Science+Business Media New York 2014

World Wide Web gratefully acknowledges the editorial work of the following scholars:

- Wojciech Cellary, Poznań University of Economics

- Louis Freund, San José State University

on this special section on The Human Side of Service Engineering.

The papers in this section include:

- "ICT Services for Open and Citizen Science" by Mikolaj Morzy

- "Automatic Summarization of Risk Factors Preceding Disease Progression: An Insightdriven Healthcare Service Case Study on Using Medical Records of Diabetic Patients" by Pei-Yun S. Hsueh, Xin Xin Zhu, Mark J. H. Hsiao, Selina Y. F. Lee, Vincent Deng, and Sreeram Ramakrishnan

- "Service Economy, Knowledge, and the Need for T-shaped Innovators" by Sergio Barile, Marialuisa Saviano, and Cristina Simone 